Torp, O., Bølviken, T., Aslesen, S., Fritzsønn, L. P., Haagensen, Å., Lombardo, S., and Saltveit, T. (2018)."Is Integration of Uncertainty Management and Last Planner System a good idea?" In: Proc. $26^{\text {th }}$ Annual Conference of the International. Group for Lean Construction (IGLC), González, V.A. (ed.), Chennai, India, pp. 658-668 DOI: doi.org/10.24928/2018/0218. Available at: www.iglc.net.

\title{
IS INTEGRATION OF UNCERTAINTY MANAGEMENT AND THE LAST PLANNER SYSTEM A GOOD IDEA?
}

\author{
Torp, Olav ${ }^{1}$, BølvikenTrond ${ }^{2}$, Aslesen, Sigmund ${ }^{3}$, Fritzsønn, Lars Petter ${ }^{4}$, \\ Haagensen, Åse ${ }^{5}$, Lombardo, Sebastiano ${ }^{6}$ and Saltveit, Tobias $^{7}$
}

\begin{abstract}
The Last Planner System (LPS) is a tool for project planning and control, and is an important contribution from Lean Construction. LPS focuses on scheduling, task coordination and time management. Uncertainty Management (UM) is a key element in Project Management, where uncertainty is the totality of opportunities (potential upsides) and risks (potential downsides). UM addresses all types of uncertainty (related to cost, time, quality, scope, safety, customer satisfaction, company reputation, etc.). The aim of $\mathrm{UM}$ is to exploit the opportunities and reduce the risks.

Two construction companies involved in this research are working with both LPS and UM. One has extensive experience with LPS, but less experience with UM. The other has extensive experience with UM, but less experience with LPS. Two questions are raised and discussed in the paper: 1. Could project planning and control be improved by an integration of LPS and UM? 2. If yes, how could LPS and UM be integrated to improve project planning and control?

The paper proposes a conceptual model where UM tools are integrated in the plan and meeting structure of LPS. The model is to be tested in forthcoming case studies.
\end{abstract}

\section{KEYWORDS}

Uncertainty Management, Risk, Last Planner System

Associate Professor, Norwegian University of Science and Technology, Trondheim, Norway, +4793422673, olav.torp@ntnu.no

2 Director, Strategy, Improvement, HR and HSE, Veidekke Entreprenør AS, Norway; Also Professor at the University of Agder, Norway, +47 90968 043, trond.bolviken@ veidekke.no

3 Research and Development Manager, Team Veidekke DA Ulven, Veidekke Entreprenør AS, Oslo, Norway, +47 92218 492, sigmund.aslesen@ veidekke.no

4 Project Director, AF gruppen, Oslo, Norway, +47 97160 478, larspetter.fritzsonn@afgruppen.no

5 Risk Manager, AF gruppen, Oslo, Norway, +47 99791 529, ase.haagensen@ afgruppen.no

6 Associate Professor, Norwegian Business School, Oslo, Norway, +47930 12 003, sebastiano.lombardo@bi.no

7 Design Manager, AF gruppen, Oslo, Norway, +47 91829 331, tobias.saltveit@afgruppen.no 


\section{INTRODUCTION}

The Last Planner System (LPS) is a method to execute planning and control of construction projects. LPS is mainly a scheduling system, focusing on activities, their sequence and their dependencies in time (Ballard 2000, Ballard and Tommelein 2016). Handling uncertainty is one of the key factors for successful project management (PMI 2013, Hillson 2004, Chapman and Ward 2003). In traditional Project Management literature, Risk or Uncertainty Management (UM) has developed as an important activity and Risk Management is one of the core competence areas in Project Management (PMI 2013).

Klakegg et al. (2017) argue that an increased and explicit focus on uncertainty has something to add to LPS. This is in line with Wehbe \& Hamzeh (2013) and Aslesen et al. (2013). The latter propose to extend LPS to include safety risk management by including safety risk considerations on each of the plan levels of LPS. The argument is that accidents and injuries on the construction site are deeply intertwined with the workflow that LPS seeks to control. We suggest that it is worthwhile to build further on this reasoning. We do however propose that the concept of safety risk discussed by Aslesen et al. (2013) could be extended to the broader notion of uncertainty. The main reason is that whereas safety is only about preventing negative outcomes (risks) in the form of accidents, uncertainty, whether related to costs, progress, quality, corporate reputation or health, also includes the possibility of positive outcomes. Example of an opportunity for a construction project could be that during the ground works, one reveals that the ground conditions is better than expected. This leads to less costs and less time used on ground works. To deal with uncertainty requires a more balanced approach where analyses and management of risk can be counterbalanced by investigations of opportunities to avoid a one-sided focus on all the things that might go wrong.

This study aims to explore the opportunity of using UM to broaden the scope of LPS. The following research questions are addressed:

- Could project planning and control be improved by an integration of LPS and UM?

- If yes, how could LPS and UM be integrated to improve project planning and control?

\section{RESEARCH METHODOLOGY}

The aim of this paper is to develop a framework for how UM and LPS could be integrated. Given this aim, a qualitative approach was chosen. A literature review was done, searching for the research gaps for LPS and for UM, and literature discussing a possible integration of the two. A series of workshops were held to discuss how it could be possible to integrate UM and LPS, including representatives from academia and the two construction companies involved in the research. The workshops were used to discuss the advantages and disadvantages of integrating LPS and UM, and to discuss possible ways of integrating the two. Since this is a theoretical study where our aim is to propose a framework for integration of LPS and UM, no case studies are included this far. 
Torp, Olav, BфlvikenTrond, Aslesen, Sigmund, Fritzsфnn, Lars Petter, Haagensen,

Ase, Lombardo, Sebastiano and Saltveit, Tobias

\section{THEORETICAL BACKGROUND}

\section{UNCERTAINTY MANAGEMENT}

There are several definitions of the terms uncertainty (Galbraith 1977, Andersen 2005, Hillson 2004, Johansen 2015). In this paper, the following definition of uncertainty is used: Uncertainty is an event that if it occurs, has a positive (potential upsides or opportunities) or negative (potential downsides or risks) effect on a project's objectives (PMI 2013). Uncertainty Management processes aim to reduce the risks and exploit the opportunities (Hillson 2004).

Uncertainty can be either statistically describable variation or single event uncertainty (Ballard and Vaagen 2017). Statistically describable variation is variability in time, cost, etc. of events that will happen, while event uncertainty is described by probability and consequence of possible events that might and might not happen. An example of statistically describable variation for the main contractor is the price he will get from the sub-contractors. Whether a sub-contractor would go bankrupt during the project is a single event uncertainty.

Uncertainty Management (UM) includes both proactive, interactive and reactive ways of thinking. Proactive UM is about analysing the uncertainty upfront to make actions before things happens. Interactive UM is about being able to handle things as they happen. Reactive UM is about understanding things that have happened, it is about repairing, exploiting opportunities and gathering experiences for future learning.

A number of Uncertainty Management processes are described in the literature (Raz \& Hillson 2005, Chapman and Ward 2003, PMI 2013). Torp et al. (2007) propose an Uncertainty Management Process with the following five steps; Uncertainty Management Planning, Perform Uncertainty Analyses, Handling/Treat Uncertainty, Uncertainty Monitoring and Evaluating the Uncertainty Management Process. Typical tools for Uncertainty Management are stochastic cost or time estimation, scenario analysis, SWOT-analysis, single event uncertainty analysis, uncertainty matrices, uncertainty registers and different treatment strategies and action plans (Hillson 2004, Chapman and Ward 2003, Lichtenberg 2000). These tools are used with an aim either to quantify the size of the uncertainty or to prioritize between different uncertainties (Lichtenberg 2000). One result from the uncertainty analyses is a list of the identified uncertainties and their impact on the project objectives. This list is called the uncertainty register and includes all relevant information about the uncertainties, their size and possible impacts. From the uncertainty register a shortlist of the most important uncertainties is formed. This shortlist is also referred to as the focus list, the priority list, the top-10 list or the uncertainty profile.

An uncertainty analysis meeting, a gathering of a group of experienced people, is described by Lichtenberg (2000), establishing the basis for the uncertainty register. Uncertainty management includes a series of uncertainty analyses, and a series of uncertainty management meetings, where the uncertainty register and the focus list are updated. The length of the periods can vary, but for a large project uncertainty management meetings are typically held two to four times a year. 
Much literature focuses on overall uncertainty management processes (Hillson 2004, Chapman and Ward 2003), typically on a project-owner level. How to operationalize uncertainty management in weekly and daily project planning and control activities is not well described. How is for instance the focus list for a project operationalized for each phase of a project, to each contract and then to operational plans for the supervisors and workers?

\section{THE LAST PLANNER SYSTEM}

The Last Planner System (LPS) is a system developed for the planning and control of project-based production (Ballard 2000). The system is based on the following principles (Ballard et al. 2009):

- Plan in greater detail as you get closer to doing the work

- Produce plans collaboratively with those who will do the work

- Reveal and remove constraints on planned tasks as a team

- Make and secure reliable promises

- Learn from breakdowns.

The Last Planner refers to the planners last in a chain of planners, in a construction project typically the supervisor, squad leader or even the trade workers. The system is based on their involvement in the planning and control of the project's progress. A fundamental recognition is that due to the high degree of variability characterizing construction production, decision-making is best done by letting those closest to the operations have substantial influence on scheduling. Even more so, the last planners are the key to produce good assignments (Ballard 1993). For them to fulfil their role, the system advocates a shielding process distinguishing what "should" be done, from what "can" be done, and what "will" be done (Ballard 2000). This is done by introducing several levels of planning, to make people "look ahead" and make sure all necessary preconditions are in place before a task is assigned to the workers on site. The shielding process, thereby, shields the last planners from an erratic flow of resources.

As originally presented by Ballard (2000) LPS consists of four levels of plans: The master schedule (made once, covering the whole project), the phase schedule (made once, covering one phase), the look-ahead schedule (continually updated, covering the next 6-9 weeks) and the weekly work plan(continually updated, covering the next $1-2$ weeks) ${ }^{8}$. In practice, this also constitutes a meeting structure and a structured division of labour in the planning and control process. Different people in different meetings handle different plans.

LPS constitutes a proactive make-ready process where tasks can be seen as traveling top down through the plan and meeting structure. Along this travel,variability (uncertainty) is gradually reduced and constraints are removed, allowing only sound tasks

\footnotetext{
${ }^{8}$ Versions with five and six levels have later been developed.
} 
Torp, Olav, BфlvikenTrond, Aslesen, Sigmund, Fritzsфnn, Lars Petter, Haagensen, Ase, Lombardo, Sebastiano and Saltveit, Tobias

to be released for execution ${ }^{9}$. This way LPS has a fundamental top-down functionality. However, it also facilitates local handling on each plan level and bottom-up processes.

\section{INTEGRATION OF LPS AND UM INTO ONE SYSTEM}

\section{IS INTEGRATION OF LPS AND UM A GOOD IDEA OR NOT?}

Klakegg et al. (2017) find that some of the basic ideas UM and LPS are based on are the same and that an increased and explicit focus on uncertainty can add value to LPS. By bringing people together to integrate all efforts toward a common objective, a plan should point more directly to difficult and significant activities, to uncertainties, and not least to the problems of achieving the objective. For a start, construction management must apply plans, which tell with as much accuracy as possible how the efforts of the people representing various functions should be directed toward the project's completion. To succeed, however, management must not only be able to collect all pertinent information to form a basis for prediction and planning. Likewise, it is important to evaluate alternative plans for accomplishing objectives. Construction management is not so much about defining the perfect plan as it is about developing a plan that will work under varying circumstances.

LPS deals with reduction of variability in the work flowby proactive project planning and control. This enables activities to be sound and made ready to be done. Ballard and Vaagen (2017) introduce a framework to manage variation in a project, where both statistically described variation and single events are handled. The main ways of handling statistically described variation are to reduce variation in stable processes, buffering of variations not reducible and redesign unstable processes, while single event uncertainties are handled by including flexibility in teams or flexibility in plans. Therefore, LPS offers a proactive approach to reducing variability, an interactive approach, handling what happens, but also includes reactive tools, e. g. to learn from what happened by calculating PPC and asking 5 whys.

Klakegg et al. (2017) see look-ahead planning as the mechanism in LPS that in the most concrete and systematic way seeks to eliminate causes of uncertainty by checking for preconditions and thereby securing sound activities. This is in line with Wehbe\&Hamzeh (2013), who propose a framework for integrating Failure Mode and Effects Analysis (FMEA) as an addition to constraints removal in the look-ahead planning. In look-ahead planning, specific measures for reducing the impact of events that could create problems should be identified and implemented. This logic should also be applied in the weekly work plan.

The following similarities and differences between LPS and UM are observed:

- Both LPS and UM aim to reduce variability in time;

9 A sound task is a task where all preconditions for doing the task in an efficient way are present. Koskela (1999) presents seven preconditions for a task to be sound, often referred to as "the seven preconditions" (materials, labor, equipment/tools, pre-requisite work, space, information, and external conditions). 
- While LPS focuses on schedule uncertainties (uncertainty in the work flow and the flows of resources feeding the work flow), UM focuses on all types of uncertainty (uncertainty in income, procurement costs, quality, safety, corporate reputation, etc.).

- LPS focuses on the preconditions for sound activities (typically the seven preconditions described by Koskela (1999)), while UM focus on the most important uncertainties, prioritized through uncertainty analyses.

- LPS focuses on reducing waste, and hereby reducing variability, while UM in addition aims to exploit opportunities that occur in the project; and

- UM also covers, in addition to variability, analysis and management of single event uncertainty. (Originally, the focus on waste reduction came from industrial production and was often shielded from event uncertainty, while single events were more relevant to project-based production.)

An important question is how uncertainties are prioritized when focusing on the preconditions for sound activities in LPS. UM might help prioritizing the most important uncertainties in LPS, not only importance for schedule, but also for other factors such as cost and quality. Other important questions are; what are the relationships between the different plan levels, and how can we secure that the weekly work schedule and lookahead schedule are in compliance with the milestones in the phase schedule and again in the master schedule? And how can we integrate the focus on schedule with the focus on cost and quality so that UM helps focusing on the right uncertainties/variability on all levels?

An important issue in UM is how to transfer the focus list down to the operational level. Another is how to achieve a balanced focus on opportunities and risks instead of ending up with a one-sided focus on risk alone. We think that integration of UM into the plan and meeting structure of LPS would help operationalize UM and to some degree solve some of the described challanges. Based on this, we conclude that integrating UM and LPS could be a good idea. In the next chapter, a framework for how this could be done is presented.

\section{HOW COULD LPS AND UM BE INTEGRATED INTO PROJECT PLANNING AND CONTROL?}

Klakegg et al. (2017) proposes the following regarding how elements of UM could be integrated into different levels of plans in LPS: In the master schedule a probability-based approach could be used. As a follow-up to this, the phase schedule meeting can be used as an arena for identifying uncertainties for all disciplines and for raising awareness about measures for limiting the probability of something going wrong. Physical measures and control points for following up high-risk events can be shown explicitly in the phase schedule. The uncertainty matrix and uncertainty register should be updated in the phase schedule meeting. The phase schedule perspective on a good work sequence for all the disciplines represents an opportunity perspective.

Together with the meeting structure and corresponding organizational levels, the different plan levels of LPS form an effective structure for production planning and 
Torp, Olav, BølvikenTrond, Aslesen, Sigmund, Fritzsфnn, Lars Petter, Haagensen, Ase, Lombardo, Sebastiano and Saltveit, Tobias

control. From UM, the uncertainty analysis meeting is an arena for discussing, quantifying and prioritizing uncertainties. Typically this kind of uncertainty analysis is done for the project owner prior to the final decision to start the project; for the contractor it is done prior to delivering the tender and as a part of establishing the master schedule. The master schedule will offer input to LPS, and uncertainty analysis done prior to delivering the tender will function as input to the first version of the uncertainty register and the focus list.

We suggest using the LPS meeting structure as a framework to link UM and LPS. An important issue is what kind of uncertainty that can be managed by LPS. From the uncertainty focus list, different kinds of uncertainties can be identified and prioritized. It might be relevant to handle some of them in the meeting structure of LPS, others might best be handled in other arenas, e.g. by the owners decision plan. In the rest of the paper only uncertainties that could be handled through the LPS meeting structure are considered.

A potential improvement of UM, as discussed earlier, is the operationalization of UM down through the different levels of planning. A focus list should be established at the level of the master schedule. The list should not only consider schedule uncertainties, but give an overall picture of the top uncertainties for the project. The uncertainties on the list, both positive and negative, should if possible be estimated in monetary values.

The relevant uncertainties in the focus list on the level of the master schedule should be transferred down, concretized and translated to the phase schedule. In addition new uncertainties could be identified at this planning level and added to the uncertainty register (and if they are important enough, to the focus list). Next would be to translate and operationalize the focus list to the look-ahead level. Again, the focus list should be translated, specified and presented in a way that makes it possible for larger parts of the organization to take part in the mitigation and elimination of risks and the realization of opportunities. Moving to the level of the weekly workplans, the translation process should be carried out once more. This way, a separate focus list is established at all plan level. The list should build on the corresponding list on the higher level, but reformulating (translating) the uncertainties if needed in order to make them relevant, understandable and manageable at the level in question. Through this top down process, the entire organization could be mobilized in a better way to manage uncertainty, see Figure 1. 


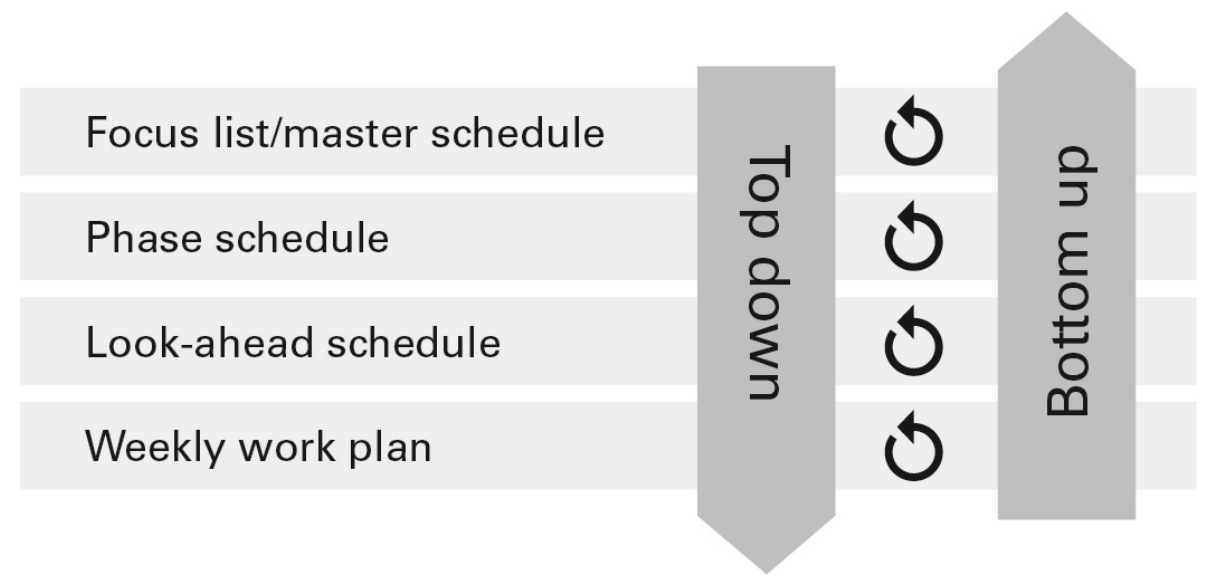

Figure 1: Top down, bottom up and local management of uncertainty integrated into LPS.

In the above-described process, there would be different ways of handling and transforming uncertainties. This also has to be seen in relation to the organizational level that owns the different plans. Some uncertainties could be handled on the level on which they are identified, and not transferred down to the underlying levels. Some uncertainties could or should be handled outside LPS. Some uncertainties are translated and transferred down to the next plan level. Other uncertainties might not be a part of the focus list, but could occur on the operational level. Some of these might be handled on the operational level, others might be necessary to handle at a higher organizational level.

As you move to the more detailed levels, uncertainty management is more about handling risks, and not so much about exploiting opportunities. The discussion is about constraints and preconditions for sound activities, and not so much about improvements. In Lean terms, the opportunity perspective could be expressed as waste reduction or increase of value. At the level of the look-ahead schedule or weekly work schedule, the focus is mainly on waste reduction. Prior to the phase schedule meeting, look-ahead meeting and the weekly work schedule meeting, the coordinator of the meeting, in preparation for the meeting, needs to translate the focus list from the level above. The owner of the meeting also needs to set the agenda for the meeting at his level. This process is illustrated in Figure 2.

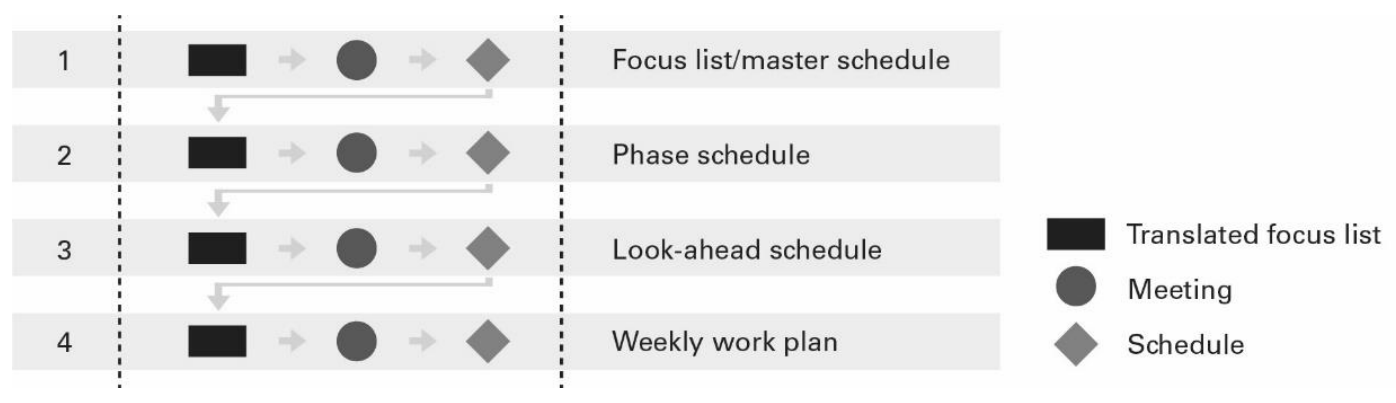

Figure 2: Top down translation of uncertainties.

One example of risk for a main contractor is procurement of sub-contractors. During the bidding process, the sub-contractor market is uncertain(price, quality, solidity, 
Torp, Olav, BølvikenTrond, Aslesen, Sigmund, Fritzsфnn, Lars Petter, Haagensen, Ase, Lombardo, Sebastiano and Saltveit, Tobias

cooperation etc.). This will be reflected in the master schedule, and in the focus list from uncertainty analysis. Some risk-reducing measures could be identified at the master schedule level, such as the market survey. During phase planning, this risk could be concretized as different risks related to the sub-contractor being considered, where one risk could be the possibility of the plumber going bankrupt. There are some signs seen by the main contractor that this specific sub-contractor struggles with the economy. In the phase-plan analysis, the best case is when the sub-contractor does his work without any problems. The most likely case is that the sub-contractor survives, but there will be some problems with the schedule and low quality deliveries. The worst case scenario is bankruptcy and the need for a new sub-contractor to replace the plumber. In the lookahead schedule meeting, this risk could be translated and reformulated to compliance and commitment to the plan, with the best case scenario that everyone do as planned, the most likely scenario that some parties do not follow the plan, and the worst case scenario that one party is far behind the plan. Risk reducing activities at this level could be that the main contractor asks for a manpower plan and a procurement plan for the main materials and deliveries from the large sub-contractors. In the look-ahead process, the main contractor can observe the sub-contractor and his manpower and logistic flow. An observation could be that the plumber starts working with the wrong activities - typically activities where he get paid by the hour - without buying materials. The risk is concretized and translated into the uncertainty register at weekly work schedule level, as lack of deliveries by sub-contractors. These might not be described by scenarios, but this is a risk to be followed up by the site manager and his internal foremen. Risk reducing measures could be that the main contractor supports the sub-contractor by providing materials directly to the supplier, and identifying buffer areas where the general contractor's own people and other sub-contractors can work while waiting for the plumber to do his work. Another measure is that the main contractor asks the plumber to be represented by his project manager in addition to the foreman in the look-ahead meeting. At the weekly work schedule meeting, real work done by the plumber is observed. Problems will be visible in PPC-measurement and actions can be taken before serious problems arrive. Depending on the level of the problem, actions can be taken in weekly work schedule meetings or raised to the look-ahead meeting. If the plumber is very close to or even goes bankrupt, risk mitigation needs to be done on the strategic organizational level, where the project manager or site manager needs to handle uncertainty, giving a reactive perspective.

\section{DISCUSSION AND CONCLUSION}

In this paper we have discussed similarities and differences between LPS and UM and proposed a way in which LPS and UM could be integrated into one system. Our proposal is to do this by translating the relevant uncertainties on the focus list of the project to the different levels of planning in LPS. Today, UM is mainly seen as an activity in the top project management group. By extending UM to all the levels of planning in LPS, we seek to engage the entire project organization in the UM process of reducing risk and exploiting opportunities. 
There are however, some important issues that must be assessed and tested before concluding whether or not our proposal will work or not in practice (Klakegg et. al 2017):

- Is there a risk that loading even more tasks onto LPS may result in dilution?

- Which specific questions concerning uncertainty should be asked at the different planning levels and how should the answers be documented, communicated and followed up?

- Will the translation of the focus list to the different plan levels in LPS function in practice?

- Is LPS equally suitable for managing all types of uncertainty or are there specific types of uncertainty that demand other approaches?

We plan to test the concept in case studies in both construction companies involved in the present paper. Our ambition is to present the results from the case studies at the forthcoming IGLC conference in 2019.

\section{ACKNOWLEDGEMENTS}

Thank you to Glenn Ballard for attending one of the workshops where the contents of this paper was discussed and developed.

\section{REFERENCES}

Andersen, Erling (2005). Prosjektledelse - et organisasjonsperspektiv. Oslo. NKI-forlaget. Aslesen, S., Sandberg, E., Stake, S. \& Bølviken, T. (2013). Integrating Safety Analyses in Production Planning and Control - A Proposal. In: Proc. 21st Ann. Conf. of the Int'l. Group for Lean Construction. Fortaleza, Brazil

Ballard, G. (2000). The Last Planner System of Production Control. Ph.D. Diss., School of Civil Engineering, The University of Birmingham, UK.

Ballard, G., Hammond, J., \& Nickerson, R. (2009). Production Control Principles. In: Proc. of the 17th Ann. Conf. of the Int'l. Group for Lean Construction. Taipei, Taiwan

Ballard, G. \&Tommelein, I. (2016). Current Process Benchmark for the Last Planner System. The Project Production Systems Laboratory (P2SL), The University of California Berkeley, USA. Available at p2sl.berkeley.edu

Ballard, G. \&Vaagen, H. (2017). "How research Can Help Transform the Construction Industry" Project Flexibility in Lean Construction. Proceedings of the 25th Annual Conference of the International Group of Lean Construction (IGLC). Heraklion, Greece.

Chapman, C. \& Ward, S. (2003). Project Risk Management; John Wiley \& Sons Ltd.: Hoboken, NJ, USA.

Galbraith, J. K. (1977). Organizational Design: An information Processing View. Organizational Effectiveness Center and School.

Hillson, D. (2004). Effective Opportunity Management for Projects: Exploiting Positive Risk; Marcel Dekker Inc.:New York, NY, USA. 
Torp, Olav, BølvikenTrond, Aslesen, Sigmund, Fritzsфnn, Lars Petter, Haagensen,

Ase, Lombardo, Sebastiano and Saltveit, Tobias

Johansen, A. (2015). Project Uncertainty Management a New Approach-The "Lost Opportunities". Ph.D. Thesis, Norwegian University of Science and Technology, Trondheim, Norway.

Klakegg, O. J; Torp, O; Kalsaas, B. T; Bølviken, T. and Hannås, G. (2017). Usikkerhetsstyring - et utviklingsområde for Lean Construction. In Kalsaas, B. T. (editor). Lean Construction. Forstå og forbedre prosjektbasert produksjon. Fagbokforlaget, Bergen, Norway. (In Norwegian. A translation to English is available from the authors.)

Koskela, L. (1999). "Management of Production in Construction: A Theoretical View." Proceedings of the 7th annual conference of the International Group for Lean Construction, Berkeley, CA, USA.

Koskela, L. (2000). An Exploration towards a Production Theory and its Application to Construction. VTT Technical Research Centre of Finland

Lichtenberg, S. (2000). Proactive management of uncertainty using the successive principle. A practical way to manage opportunities and risks.Lyngby. Polyteknisk Press.

Project Management Institute. (2013). Project Management Body of Knowledge; Project Management Institute: Newtown Square, PA, USA.

Raz, T.; Hillson, D. A comparative review of risk management standards. Risk Manag. Int. J. 2005, 7, 53-66.

Torp, O.; Karlsen, J.T.; Johansen, A. (2007). TeoretiskRammeverk for Usikkerhetsstyring (Theoretical Framework for Uncertainty Management); The Research Project PUS, NTNU-Report; NTNU: Trondheim, Norway. (In Norwegian)

Wehbe, F. A. and Hamzeh, F. R. (2013). Failure mode and effect analysis as a tool for risk management in construction planning. Proceedings of the 21st Annual Conference of the International Group of Lean Construction (IGLC). Fortaleza, Brazil. 